New DFG head vows to back Germany's young scientists - and genetics research

[MUNICH] Concern for Germany's future scientists and a strong commitment to European collaboration in basic research are likely to characterize the three-year term of Ernst-Ludwig Winnacker (above) as president of the Deutsche Forschungsgemeinschaft (DFG) research council.

His appointment means that the DFG, which distributes grants to Germany's university researchers, will also remain firmly in egalitarian hands, as Winnacker like his predecessor, Wolfgang Frühwald believes that the entrenched traditional hierarchical culture of German science is counterproductive.

An internationally respected molecular virologist, Winnacker, who takes up his post at the beginning of next year, received his PhD from the Swiss Institute of Technology in Zurich in 1968. He was the first to clone the nuclear factor (NF1) gene involved in the control of transcription.

After pursuing research at the Karolinska Institute in Stockholm, at the University of California, Berkeley, and at the Institute of Genetics in Cologne, he was appointed to a chair in biochemistry at the Ludwig Maximilians University in Munich, where he has spent the past 20 years, and is currently director of the Genzentrum München.

Although Winnacker's first career choice was music - he plays the cello and the piano - he says he has no regrets about abandoning this for science. But life as a molecular biologist has not always been easy in Germany, where genetic engineering has faced aggressive and articulate opposition.

His energetic participation in public debates in defence of research, and a parliamentary advisory committee on genetic engineering from 1984 to 1987 , resulted in Winnacker being placed on a hitlist by an extremist group, and he was under police protection for two years.

Despite the recommendations of the parliamentary committee, Germany introduced heavily restrictive rules on genetic engineering in 1990. But since then genetic engineering has been slowly gaining public acceptance, at least in medicine, and the rules were relaxed in 1993.

Winnacker describes the DFG as being "in excellent shape". But he has many ideas about areas of DFG policy where he would like to see improvements. At the top of the list is the possibility of expanding the council's programmes for young scientists.

He is keen to address the scope for awarding grants for periods of perhaps up to five years, in addition to the two-year norm. This would give research continuity, and help to reverse the trend towards

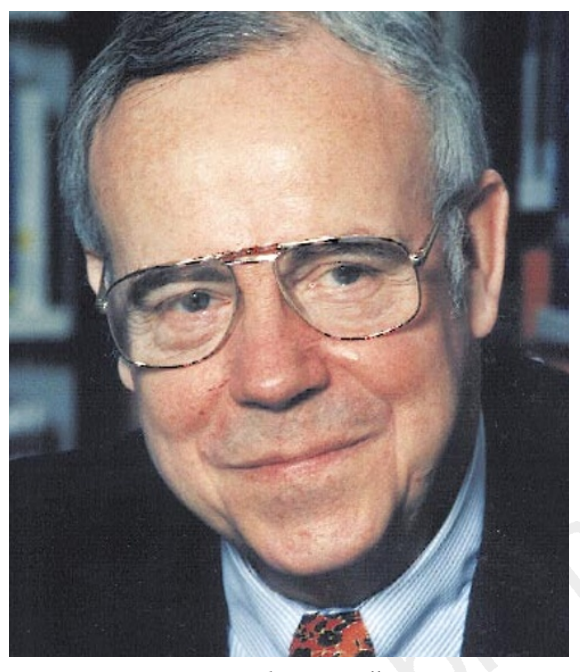

excessive reviewing, he says. "Sometimes I feel that we are spending all our time reviewing each other rather than working."

Winnacker also wants to see whether the large number of DFG specialist review committees - there are 37 - could be reduced or restructured to promote interdisciplinary approaches to science.

Winnacker has strong views on European research policy. He says that although the frequently proposed creation of a single European research council for basic research would be premature, given differences in research infrastructure between rich and poor countries, national research organizations should allocate some of their budgets to a joint fund to support collaborative projects (as the DFG already does with Israel and Palestine).

He also wants the DFG to become more directly involved in promoting public understanding of science. Part of the reason that genetics has had a bad press in Germany, he says, is that scientists do not describe to people what they actually do.

He practises what he preaches. He is the author of two popular books on genetics, and is working on a children's book about the life of a gene.

Winnacker considers his most important achievement to be the creation of the Genzentrum, one of three genetics centres established in the early 1980s with federal research ministry funding. The centre's building on the edge of Munich houses 80 scientists. The site is next to two Max Planck research institutes, and near Munich's largest teaching hospital. It will soon be joined by the university's entire faculty of science. This concentration of scientists was part of Winnacker's goal: "Critical mass is fundamental for successful science," he says, arguing that faculties in German universities tend to be too small.

\section{Energy laboratories to open joint DNA sequence 'factory'}

[SAN FRANCISCO] The US Department of Energy's Joint Genome Institute, a programme combining genomic research at three national laboratories, is to set up a high-throughput DNA-sequencing factory.

The factory, a joint effort by the Lawrence Livermore, Lawrence Berkeley and Los Alamos national laboratories, will be based in Walnut Creek, California, in the San Francisco Bay area. It represents a commitment to increase the three laboratories' screening capacity and so create a major contributor to the worldwide effort to sequence the human genome by the year 2005 .

About 200 technicians and researchers will work three shifts around the clock, employing state-of-the-art robotics. Technology development and other research will continue at each laboratory. "The purpose is to [make sequencing] highly efficient and very cheap," says Elbert Branscomb, scientific director of the Joint Genome Institute.

The Department of Energy was the first federal agency to fund an initiative to unravel the entire genome. The impetus for this move grew out of its interest in detecting rare genetic changes that may result from exposure to toxic or radioactive substances. Until now, however, the national laboratories have lagged behind other major sequencing laboratories.

By the end of the current fiscal year in September, the three laboratories are likely to have contributed only about 3 million bases to the public databases, out of a total of 3 billion bases in the human genome. They hope, however, to increase that figure to 20 million by the end of next year, comparable to the most productive laboratories in the country.

The Joint Genome Institute, founded last year, represents a radical change in the laboratories' way of working, says Branscomb, with a shift from competition to collaboration between them. "The essence is breaking down the barriers between the labs," he says.

Historically, biological research programmes at the laboratories have been small compared with the applied physics and chemistry on which they built their reputations. The Joint Genome Institute has requested $\$ 40$ million for programmes next year at the three laboratories and the sequencing factory, a $\$ 10$ million increase on the current fiscal year.

Branscomb says that the sequencing factory will adhere to stringent public disclosure procedures on its work, with immediate postings on the web regarding smaller pieces, and full clones submitted nightly to the public databases.

SallyLehrman 